\title{
Transient ischemic attack as the initial presentation of Takayasu arteritis in a young woman: A case report
}

\author{
Dren Boshnjaku ${ }^{1,2}$, Fisnik Jashari'1,2, Bujar Gjikolli ${ }^{3}$, Edmond Komoni ${ }^{1,2}$, Melihate Pushka', \\ Argjend Shala ${ }^{1,2}$, Vera Kukaj ${ }^{1,2}$, Nexhmedin Shala, \\ ${ }^{1}$ Clinic of Neurology, University Clinical Center of Kosovo, Prishtina, Kosovo \\ ${ }^{2}$ Medical Faculty, "Hasan Prishtina" University of Prishtina, Prishtina, Kosovo \\ ${ }^{3}$ Clinic of Radiology, University Clinical Center of Kosovo, Prishtina, Kosovo
}

\begin{abstract}
Takayasu arteritis (TA) is a challenging chronic inflammatory vasculitis of large vessels with unknown etiology. It usually affects the aorta and its main branches and in few cases it affects other arteries like pulmonary and coronary. We report a case of a young woman with transient ischemic attack (TIA) as the initial presentation followed later by ischemic limb syndrome and then ischemic stroke. Lack of specific diagnostic biomarkers for this disease makes early diagnosis and treatment challenging.
\end{abstract}

Keywords: Takayasu arteritis, FLAIR, DWI, azathioprine, large vessel, vasculitis, carotid artery, middle cerebral artery, frontal-parietal lobe, occlusion

\section{INTRODUCTION}

Takayasu arteritis (TA) or "pulseless disease", was for the first time presented in 1908 by Mikito Takayasu, as a case report with retinal vasculitis and pulselessness. TA is chronic inflammatory disease, characterized by structural changes in the arterial wall resulting in stenosis, occlusion and aneurysm of the aorta and its main branches, especially subclavian $[1,2]$, common and internal carotid arteries. However, other arteries, such as pulmonary can be affected as well $[1,3]$.

TA is more frequent in Far Eastern and Asian countries, and it is relatively uncommon in northern European and American countries. It affects women more frequently than men, with a ratio of 9:1 [4]. TA cases presented with neurologic sign and symptoms are relatively common, approximately $50 \%$ of patients. However, ischemic stroke as the initial presentation of TA is very rare [5-8]. Our case presented as transient ischemic attack
(TIA), with right side weakness and dysphasia, recovered completely after several hours, and then after three days she developed ischemic stroke. Dependent on arteries involved, there are six types of TA: type I affects main branches of aortic arch, type IIa affects the ascending aorta, aortic arch and main aortic branches, type IIb affects thoracic aorta with the implication of type IIa, type III affects thoracic aorta, abdominal aorta and/or its main branches (renal arteries), type IV affects abdominal aorta and/or its main branches (renal arteries) and type $\mathrm{V}$ is the mixture of type IIb and type IV [9].

\section{CASE PRESENTATION}

A 25 years-old female, three days before hospital admission, developed speech problems and right side weakness, which lasted for several hours and then recovered. After two days she developed right arm numbness with cyanotic changes. Vascu- 
lar surgeon was consulted and occlusion of right subclavian artery was detected on arterial duplex examination. Angio-MSCT-64 scan showed brachiocephalic trunk, both common carotid and subclavian arteries occlusion on their origin. Brain arteriography was normal (Figure 1).

She was admitted in Vascular Surgery Clinic for further evaluation and treatment, but on the next day she developed right side weakness and speech problems. Brain MRI and MRA resulted in left frontal-parietal hyperintensities, T2 and FLAIR, with reduction of diffusion in DWI as characteristic for ischemic stroke, as consequence of the M1 segment in the middle cerebral artery occlusion, correlated with other findings, corresponding with the cerebral vasculitis (Figure 2).

As a result, patient was admitted in the Clinic of Neurology for further evaluation and treatment. Physical examination showed a Glasgow Coma Scale $(E 4, \mathrm{~L} 1, \mathrm{M} 6)=11$ points. Blood pressure in the right arm was 95/55 $\mathrm{mm} \mathrm{Hg}$ and left arm 130/75 $\mathrm{mm} \mathrm{Hg}$. There was a bruit on auscultation over both common carotid and subclavian arteries. His left arm was cold with weak pulses. No abnormality was detected on the chest and abdominal examination. Neurological examinations revealed motoric aphasia, supranuclear facial palsy, hemiparesis (power grade 3/5), with hyperreflexia, Trommner, Hoffman and Babinski sign were present on the right side.

Baseline investigations revealed raised erythrocyte sedimentation rate (60 $\mathrm{mm} 1 \mathrm{st}$ hour), serum C-reactive protein level was $15.1 \mathrm{mg} / \mathrm{dl}$, other analyses, including $\mathrm{CBC}$, BUN, hepatogram, lipidogram, complement, RF, ANA, ANCA, PR3, anti-DNA, thrombophilic factors, coagulation tests, were all in the normal ranges.

The patient was treated with methylprednisolone $1,000 \mathrm{mg}$ for 5 days, followed by oral dose titration, as well as oral Azathioprine $100 \mathrm{mg}$, Aspirin $100 \mathrm{mg} /$ day and Atorvastatin $40 \mathrm{mg} /$ day.
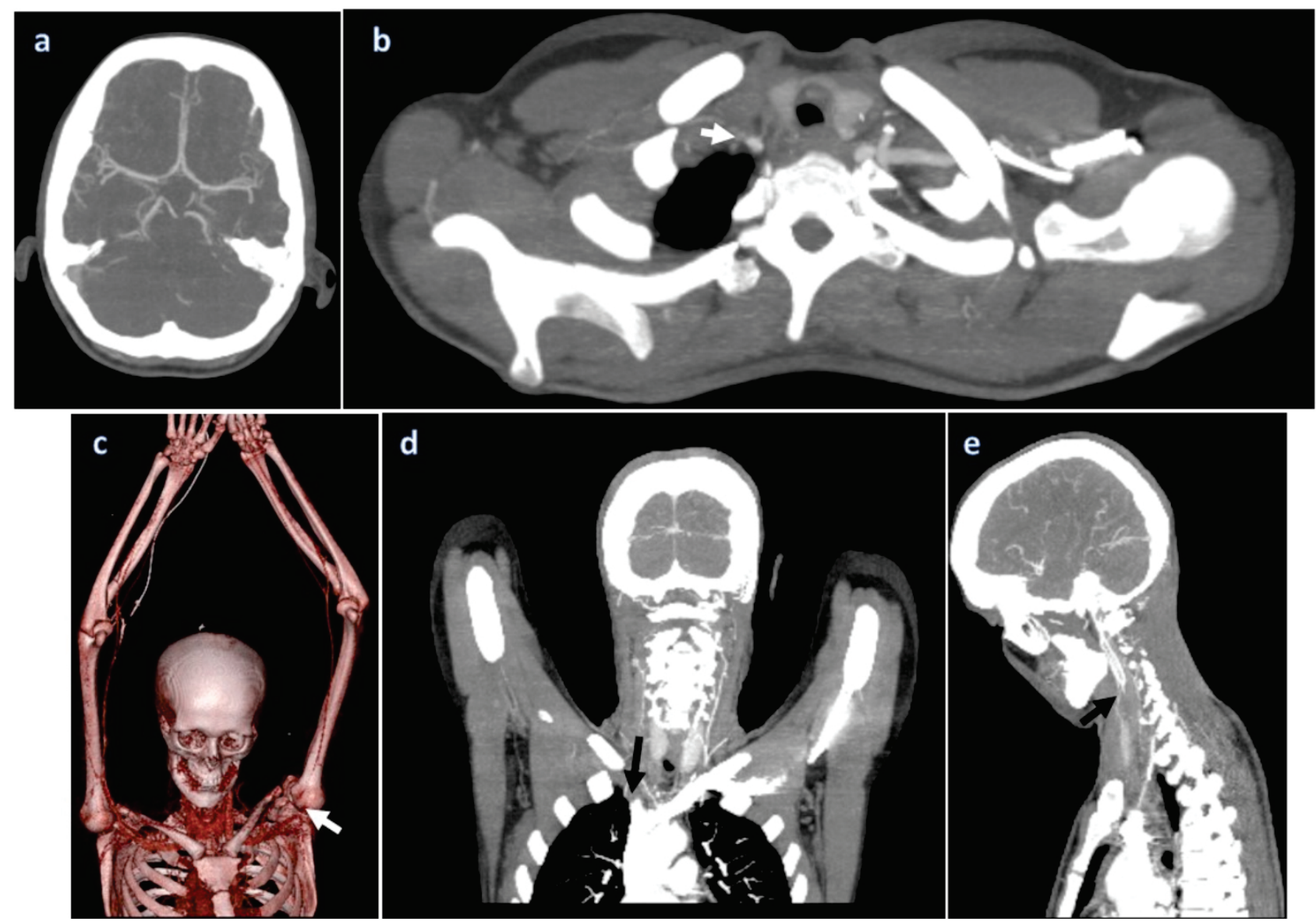

FIGURE 1. (a) CT angiography of the brain showing normal blood flow. (b) CT Artery angiography and (c) CT angiography with VRT reconstruction showing right subclavian and axillary arteries occluded on origin with collateral filling of vertebral and brachial arteries (white arrows). (d) Angio-MDCT-64 scan of the aortic arch and cervical-cerebral arteries showed brachiocephalic trunk occlusion on its proximal segment (black arrow). (e) Left common carotid artery occlusion, with collateral filling of the left internal and external carotid arteries (black arrow). 

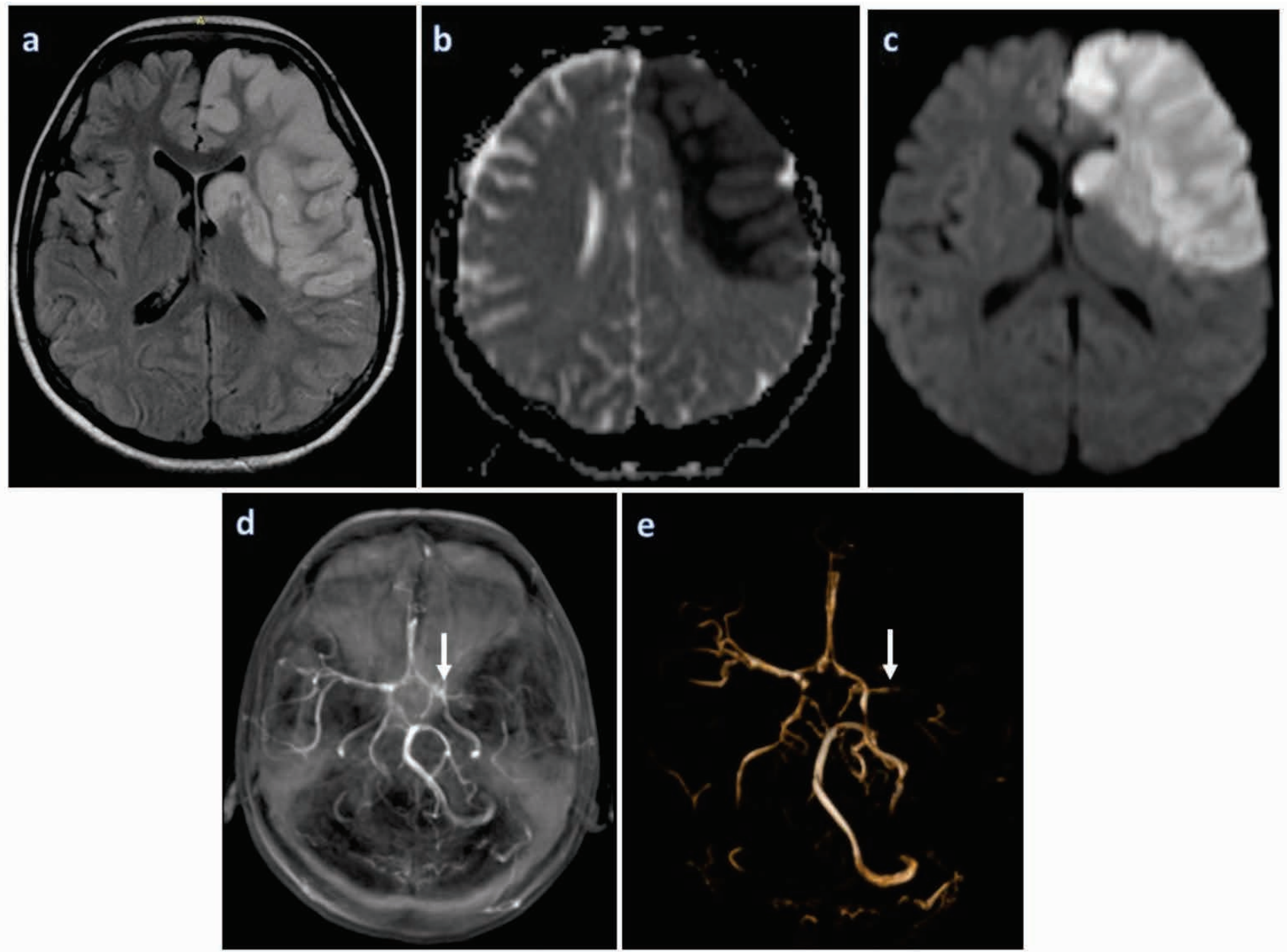

FIGURE 2. (a) MRI FLAIR brain imaging hyperintensities; (b) ADC hypointensities and (c) DWI reduction of diffusion in the left fronto-parietal lobe. (d) MRA and (e) MRA with VRT reconstruction showing middle cerebral artery (M1) occlusion (white arrows).

After consultation with vascular surgeon, the patient was sent for by pass of subclavian artery, because collateral flow was insufficient for her right arm blood perfusion.

\section{DISCUSSION}

TA is a chronic inflammatory vasculitis of unknown origin with three phases that characterize the disease. The first phase is nonspecific, distinguished by inflammatory symptoms, like fever of unknown origin (FUO), malaise, night sweats, arthralgias, anorexia, and weight loss. The second phase, marked by inflammatory process in the wall of large arteries, which reflect neck pain, caused by carotidynia, sometimes also with dorsal and thoracic pain. The third phase is characterized by decreased or absence of pulses, differences in arterial blood pressure between upper limbs, arterial bruits and intermittent claudication in extremity [10-13]. Our case met 5 out of 6 criteria for TA diagnosis based on American College of Rheumatology, which are: age less than 40, decreased brachial arterial pressure, bruit over subclavian arteries, blood pressure difference greater than 10 $\mathrm{mmHg}$ and aorta and aortogram abnormalities [14,15].

Approximately half of patents with TA may develop neurological signs and symptoms, usually with visual loss. The frequency of stroke is $10 \%$ to $20 \%$ of those patients. The mechanism of ischemic stroke is not clearly understood, it could be caused by embolism of stenotic or occlusive lesions of aorta or its principal branches, acceleration of atherosclerotic process, hypertension, embolism with cardiac origin and low cerebral blood flow. In our patient, aorta, subclavian and carotid artery were affected, suggesting type I TA, suggesting ar- 
tery-to-artery embolization or in situ stenosis with super imposed thrombosis.

Proper diagnosis and early treatment of TA are necessary to reduce morbidity, and mortality rates of the disease. Our patient had no history of generalized manifestations like malaise, fever, night sweats, arthralgia, anorexia, or weight loss, TIA was the first clinical presentation. This unspecific clinical presentation, have contributed to the delayed diagnosis of TA. Since multiple arterial branches were severely affected, the prognosis was devastating, with arm and brain ischemia. In our patient, intravenous administration of the therapy was performed even though there is recommendation to avoid intravenous drug administra-

\section{REFERENCES}

1. Kerr GS, Hallahan CW, Giordano J, Leavitt RY, Fauci AS, Rottem M, et al. Takayasu arteritis. Ann Intern Med. 1994;120:919-919.

2. Numano $F$, Okawara M, Inomata $\mathrm{H}$, et al. Takayasu's arteritis. Lancet. 2000;356:1023-1025.

3. Johnston SL, Lock RJ, Gompels MM. Takayasu arteritis: a review. J Clin Pathol 2002;55:481-6.

4. Kim H, Suh D, Kim J, et al. Correlation of neurological manifestations of Takayasu's arteritis with cerebral angiographic findings. Clin Imaging. 2005;29:79-85.

5. Numano F. The story of Takayasu arteritis. Rheumatology. 2002:41:103-106.

6. Nagasawa T. Current status of large and small vessel vasculitis in Japan. Int J Cardiol. 1996;54:S58.

7. Mason JC. Takayasu arteritis - advances in diagnosis and management. Nat Rev Rheumatol. 2010;6:406.

8. Grayson PC, Maksimowicz-McKinnon K, Clark TM, Tomasson G, Cuthbertson D, Carette S, Khalidi NA, Langford CA, Monach PA, Seo P, et al. Distribution of arterial lesions in Takayasu's arteritis and giant cell arteritis. Ann Rheum Dis. 2012;71:1329-1334.

9. Keser G, Aksu K, Direskeneli H. Takayasu arteritis: an update. Turk J Med Sci. 2018 Aug 16;48(4):681-697.

10. Vanoli M, Daina E, Salvarani C, Sabbadini M, Rossi C, Bacchiani G, Schieppati A, Baldissera E, Bertolini G. Takayasu's arteritis: a study of 104 Italian patients. Arthritis Rheum. 2005;53:100-107. tion in TA during the acute phase [16], and this might further aggravate the clinical symptoms. Therefore, TA should be considered as a differential diagnosis in young patients presented with TIA or stroke because early and proper diagnosis and treatment may prevent complications.

\section{CONCLUSIONS}

The diagnosis of TA is challenging. Although ischemic brain symptoms are relatively rare in patients with TA, it should be considered in young patients. Recommendation is to diagnose the disease as early as possible, because early and proper treatment reflects a better prognosis.

Conflict of interest: none declared Financial support: none declared

11. Bicakcigil M, Aksu K, Kamali S, Ozbalkan Z, Ates A, Karadag O, Ozer H, Seyahi E, Akar S, Onen F, et al. Takayasu's arteritis in Turkey - clinical and angiographic features of 248 patients. Clin Exp Rheumatol. 2009;27:S59-64.

12. Park MC, Lee SW, Park YB, Chung N, Lee SK. Clinical characteristics and outcomes of Takayasu's arteritis: analysis of 108 patients using standardized criteria for diagnosis, activity assessment, and angiographic classification. Scand J Rheumatol. 2005;34:284-292.

13. Grayson PC, Cuthbertson D, Carette S, Hoffman GS, Khalidi NA, Koening CL, Langford CA, Maksimowicz-McKinnon K, Monach PA, Seo P, et al. New features of disease after diagnosis in 6 forms of systemic vasculitis. J Rheumatol. 2013;40:1905- 1912.

14. de Souza AWS, de Carvalho JF. Diagnostic and classification criteria of Takayasu arteritis. J Autoimmun. 2014;48:79-83.

15. Arend WP, Michel BA, Bloch DA, Hunder GG, Calabrese LH, Edworthy SM, Fauci AS, Leavitt RY, Lie J, Lightfoot RW, et al. The American College of Rheumatology 1990 criteria for the classification of Takayasu arteritis. Arthritis Rheum. 1990; 33:1129-1134.

16. Liang P, Tan-Ong M, Hoffman GS. Takayasu's arteritis: vascular interventions and outcomes. J Rheumatol. 2004;31:102-106. 